\title{
Tailoring of Aqueous-Based Carbon Nanotube-Nanocellulose Films as Self-Standing Flexible Anodes for Lithium-Ion Storage
}

\author{
Hoang Kha Nguyen ${ }^{1}$, Jaehan Bae ${ }^{1}$, Jaehyun Hur ${ }^{1} \mathbb{D}$, Sang Joon Park ${ }^{1}$, Min Sang Park ${ }^{2, *}$ \\ and Il Tae Kim ${ }^{1, *(D)}$ \\ 1 Department of Chemical and Biological Engineering, Gachon University, Seongnam-si, \\ Gyeonggi-do 13120, Korea; hoangkhahc11dk@gmail.com (H.K.N.); jhbae1210@naver.com (J.B.); \\ jhhur@gachon.ac.kr (J.H.); psj@gachon.ac.kr (S.J.P.) \\ 2 B\&I R\&D Center, SK Innovation, 325, Exporo, Yuseong-gu, Daejeon 34124, Korea \\ * Correspondence: azopark@gmail.com (M.S.P.); itkim@gachon.ac.kr (I.T.K.); \\ Tel.: +82-42-609-8910 (M.S.P.); +82-31-750-8835 (I.T.K.)
}

Received: 19 March 2019; Accepted: 22 April 2019; Published: 24 April 2019

\begin{abstract}
An easy and environmentally friendly method was developed for the preparation of a stabilized carbon nanotube-crystalline nanocellulose (CNT-CNC) dispersion and for its deposition to generate self-standing CNT-CNC composite films. The composite films were carbonized at different temperatures of $70{ }^{\circ} \mathrm{C}, 800{ }^{\circ} \mathrm{C}$, and $1300{ }^{\circ} \mathrm{C}$. Structural and morphological characteristics of the $\mathrm{CNT}-\mathrm{CNC}$ films were investigated by X-ray diffraction (XRD), Raman spectroscopy, and scanning electron microscopy (SEM), which revealed that the sample annealed at $800{ }^{\circ} \mathrm{C}\left(\mathrm{CNT}-\mathrm{CNC}_{800}\right)$ formed nano-tree networks of CNTs with a high surface area $\left(1180 \mathrm{~m}^{2} \cdot \mathrm{g}^{-1}\right)$ and generated a conductive CNC matrix due to the effective carbonization. The carbonized composite films were applied as anodes for lithium-ion batteries, and the battery performance was evaluated in terms of initial voltage profile, cyclic voltammetry, capacity, cycling stability, and current rate efficiency. Among them, the $\mathrm{CNT}-\mathrm{CNC}_{800}$ anode exhibited impressive electrochemical performance by showing a reversible capacity of $443 \mathrm{mAh} \cdot \mathrm{g}^{-1}$ at a current density of $232 \mathrm{~mA} \cdot \mathrm{g}^{-1}$ after 120 cycles with the capacity retention of $89 \%$ and high rate capability.
\end{abstract}

Keywords: lithium-ion batteries; carbon nanotubes; nanocellulose; self-standing composite anode; carbonization

\section{Introduction}

The bi-functionality of carbon nanotubes (CNTs), i.e., their anodic activity and their role as flexible supports to provide a conductive pathway, is the reason for their application in electrode materials [1-3], given the growing interest for high-capacity and flexible energy storage and especially for lithium-ion batteries (LIBs). Lithium ions are stored on the surface or in the interior of CNTs, and their large specific surface area is favorable since it provides more space for electrolyte ion adsorption [1]. When combined with ion storage capacity, a deposit of CNTs creates a porous interconnected network that facilitates ion and electron transport and provides mechanical durability [2,3], thereby achieving a highly capable current-free anode [4].

Despite its potential, the CNT-based anode is seldom practically used in the LIB industry. In LIB manufacturing, an electrode is fabricated by casting slurry in which active materials, binders, and conductive additives are mixed together [5]. The CNT exhibits strong van der Waals interactions between nanotube sidewalls, leading to aggregates [6]. Thus, the use of an organic solvent is required, and this leads to both safety concerns and increases in production cost, thereby impeding 
its commercial use in LIBs [7]. Although several routes toward CNT dispersion in water, including chemical functionalization [8] and addition of surfactant or polymer [9], were proposed, each method exhibits a corresponding disadvantage. For example, chemical functionalization disrupts the electronic structure of the pristine nanotubes and decreases conductivity [8], and the addition of inactive materials causes a surface coverage of the CNTs, weakening inter-tubular contact for electron hopping [9]. Therefore, a method of preparing a homogenous and uniform dispersion of CNTs in water via a facile, low-cost, and green approach still remains as a challenge.

Nanocellulose attracted interest in energy storage research and is employed as a constitutive component in LIB electrodes [10]. Characteristics of nanocellulose, including nanoscale dimension and reactive surface chemistry, are conducive for combining it with nano-sized active materials, thereby providing a high specific surface area [11]. Nanocellulose also exhibits an excellent colloidal stability in water [12] and enables carbon nanomaterials, such as CNT and graphene, to disperse in aqueous media without chemical functionalization or addition of surfactant/water-soluble polymers [9,13]. Utilizing these benefits, nanocellulose was applied as a binding constitute to construct pliable self-standing $\mathrm{CNT}$ electrodes via the aqueous solution process. However, most electrodes were prepared by mixing active materials with nanocellulose with fibril foam, such as cellulose nanofibril (CNF) or bacterial cellulose (BC), due to their entangled web-like structure [14-16], and this can lead to relatively high interfacial resistance between active materials which suffers from the low dispersion limit of CNTs in aqueous media.

In the present study, we focused on nanocellulose with whisker foam, namely crystal nanocellulose (CNC). We exploited the merits of CNC including (1) a higher specific surface area than CNF or $\mathrm{BC}$ [11], and (2) a high crystalline structure that facilitates CNC's conversion into a conductive carbon by carbonization [17], which creates the binder-free effect. In the study, we developed an easy and environmentally friendly protocol involving the preparation of a stabilized CNT-CNC dispersion and its deposition to prepare a self-standing CNT-CNC film followed by carbonization. We examined the role of CNC in the composite film and its morphology changes during the carbonization. Carbonized composite films were applied as an anode and their battery performance was evaluated in terms of capacity, cycling stability, and current rate (C-rate) efficiency.

\section{Materials and Methods}

\subsection{Preparation of $C N C, C N T-C N C$, and CNT Electrodes}

CNCs (freeze-dried powders; Process Development Center, University of Maine, Orono, ME, USA) with an average length of $120 \mathrm{~nm}$ and aspect ratio of 10 were dispersed in deionized (DI) water (0.2 $\mathrm{g} \mathrm{CNC/100} \mathrm{g} \mathrm{DI} \mathrm{water),} \mathrm{and} \mathrm{the} \mathrm{surface} \mathrm{charge} \mathrm{of} \mathrm{CNC} \mathrm{was} \mathrm{dependent} \mathrm{on} \mathrm{pH}$ (Figure S1, Supplementary Materials), which affects the dispersion and stabilization of CNT (OCSIAL LLC, Columbus, OH, USA) [13]. The CNT-CNC dispersion was prepared by mixing CNT (single-walled nanotubes) powders in the $\mathrm{CNC}$-water mixture at $\mathrm{pH} 6.5$ via a bath-type ultrasonication (Figure 1).

Self-standing CNC films were simply prepared by drying the deposit dispersion consisting of $10 \mathrm{~mL}$ of solution in the petri dish at $40{ }^{\circ} \mathrm{C}$ for $6 \mathrm{~h}$, and this was followed by vacuum-drying at $70{ }^{\circ} \mathrm{C}$ for $12 \mathrm{~h}$ to remove moisture (hereafter, the $\mathrm{CNC}$ film is denoted as $\mathrm{CNT}-\mathrm{CNC} \mathrm{C}_{70}$ ). For the electrode annealed at $1300{ }^{\circ} \mathrm{C}, 40 \mathrm{~mL}$ of dispersion was used in order to obtain the well-maintained free-standing electrode, due to significant decomposition of materials at high temperature. The self-standing capability of $\mathrm{CNT}-\mathrm{CNC}_{70}$ was evaluated as ductile and sufficiently robust to withstand bending or compression. For the heat treatment, $\mathrm{CNC}_{70}$ was annealed at $800{ }^{\circ} \mathrm{C}$ and $1300{ }^{\circ} \mathrm{C}$ [17]. In brief, the $\mathrm{CNC}_{70}$ electrode was heated to $240^{\circ} \mathrm{C}$ with the heating rate of $5^{\circ} \mathrm{C} \cdot \mathrm{min}^{-1}$ and stabilized at $240{ }^{\circ} \mathrm{C}$ for $4 \mathrm{~h}$ in an $\mathrm{Ar}$ atmosphere. Afterward, it was heated to $800^{\circ} \mathrm{C}\left(\mathrm{CNC}_{800}\right)$ or $1300{ }^{\circ} \mathrm{C}\left(\mathrm{CNC}_{1300}\right)$ with the rate of $5{ }^{\circ} \mathrm{C} \cdot \mathrm{min}^{-1}$ based on the extent of decomposition and graphitization of the composite films (discussed later), respectively, and maintained at the designated temperature for $2 \mathrm{~h}$. A similar procedure was applied for $\mathrm{CNT}-\mathrm{CNC}$ electrodes, accordingly denoted as $\mathrm{CNT}-\mathrm{CNC}_{70}, \mathrm{CNT}-\mathrm{CNC}_{800}$, 
and $\mathrm{CNT}-\mathrm{CNC}_{1300}$. To compare the CNT-CNC electrodes, a bare CNT electrode was also formed by using pure CNT and a polyvinylidene fluoride (PVDF) binder. CNTs were mixed with PVDF at a weight ratio of 70:30, and N-methyl-2-pyrrolidone (NMP) was used as the solvent [18]. Specifically, CNT slurry was spread on a hydrophobic membrane and then compressed under a pressure of $10 \mathrm{~atm} \cdot \mathrm{cm}^{-2}$ for $30 \mathrm{~min}$ to form an electrode. The hydrophobic membrane was peeled after compression. Finally, the electrode was annealed at $70^{\circ} \mathrm{C}, 800^{\circ} \mathrm{C}$, and $1300^{\circ} \mathrm{C}$. Each sample was denoted as $\mathrm{CNT}_{70}, \mathrm{CNT}_{800}$, and $\mathrm{CNT}_{1300}$, respectively. With respect to the electrochemical test, the $\mathrm{CNT}_{800}$ sample was used as a bare CNT.

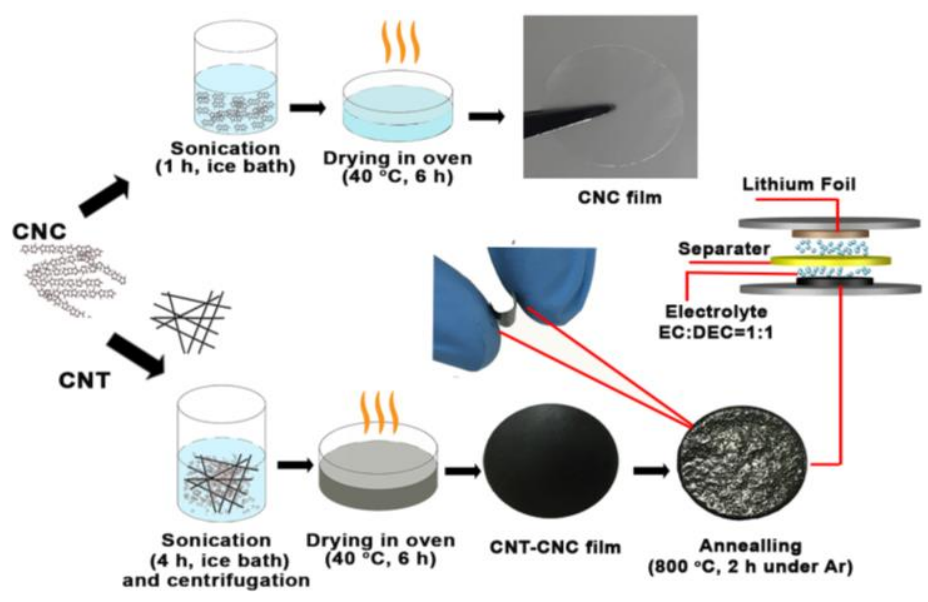

Figure 1. Schematic illustration of the free-standing electrode fabrication process.

\subsection{Material Characterization}

We evaluated the quality of CNT dispersion by exploiting the visible absorption, and we determined the amount of CNT that was stably dispersed in the CNC-water mixture based on the Beer-Lambert law [19] (see details Supplementary Materials). The ratio of CNT:CNC was identified by thermogravimetric analysis (SDT Q600 V20.9 Build 20). Resistance and conductivity measurements of the CNT-CNC films were performed using the four-point probe technique (CMT-SR1000N). The structural characteristics of the as-prepared samples were investigated by X-ray diffraction (D/MAX-2200 Rigaku, Tokyo, Japan) in the range of $20-80^{\circ}$ in the $2 \theta$ mode at the scan rate of $2^{\circ} \cdot \mathrm{min}^{-1}$. A micro Raman spectrometer (ANDOR Monora500i, $633 \mathrm{~nm}$ ) was used to evaluate the degree of crystallinity of CNT-CNC films. Morphologies of the free-standing electrodes were examined using a scanning electron microscope (SEM S-4700, Hitachi, Tokyo, Japan). For characterizing the cross-sectional morphology of the samples, they were immersed in liquid nitrogen and cryo-fractured.

\subsection{Electrochemical Analysis}

In order to examine the electrochemical properties of composite films, free-standing films at various conditions were utilized as potential anodes. After the process, each CR2032-type coin cell was assembled in an Ar-filled glove box with $\mathrm{Li}$ as the counter electrode, a sample electrode as the working electrode, and a polyethylene separator. Galvanostatic charge/discharge electrochemical tests were conducted at a constant current density of $232 \mathrm{~mA} \cdot \mathrm{g}^{-1}$ at $0.01-2.0 \mathrm{~V} \mathrm{vs.} \mathrm{Li}^{-} \mathrm{Li}^{+}$via a battery cycler (WBCS3000, WonAtech). The rate cyclic performances were tested at different charge and current densities corresponding to $100 \mathrm{~mA} \cdot \mathrm{g}^{-1}, 500 \mathrm{~mA} \cdot \mathrm{g}^{-1}, 1000 \mathrm{~mA} \cdot \mathrm{g}^{-1}$, and $5000 \mathrm{~mA} \cdot \mathrm{g}^{-1}$ under a constant discharge current density of $100 \mathrm{~mA} \cdot \mathrm{g}^{-1}$ in order to analyze fast-charge characteristics. Cyclic voltammetry testing was performed via a ZIVE MP1 (WonAtech) device in the range of 0.01-2.0 V vs. $\mathrm{Li} / \mathrm{Li}^{+}$at a scanning rate of $0.1 \mathrm{mV} \cdot \mathrm{s}^{-1}$. Electrochemical impedance spectroscopic (EIS) analysis was conducted via the ZIVE MP1 (WonAtech) analyzer by applying a 1-mV-amplitude signal in the frequency range of $100 \mathrm{kHz}$ to $100 \mathrm{MHz}$. The impedance response was measured after varying the number of cycles at $2.0 \mathrm{~V}$ vs. $\mathrm{Li} / \mathrm{Li}^{+}$. 


\section{Results and Discussion}

The prepared CNT-CNC dispersion shown in Figure S2 (Supplementary Materials) was stable even after a month of aging, while CNTs precipitated within an hour when similarly dispersed in pure water without CNCs; thus, it was unable to fabricate a bind-free anode. The determined weight ratio of CNT to CNC in the CNT-CNC dispersion was 100:11.21, as shown in Figure S3 (Supplementary Materials). The stable dispersion was attributed to the interaction between CNC and CNT as reported by Wagberg et al. [13] who hypothesized that counter-ion fluctuations on the nanocellulose surface cause assembly with CNTs and stabilize CNTs in aqueous media. Conversely, the CNT film prepared using the aqueous CNT suspension was fragile and broke easily when bent or compressed, which limited its use in the flexible electrode. The lack of flexibility was attributed to the disentanglement of CNTs. The result implied that well-dispersed CNTs in the CNC-water mixture facilitated stable networks during water evaporation.

The pyrolysis of CNC was conducted to convert the insulating CNC into conductive nanocarbons. Specifically, thermogravimetric analysis (TGA) was performed under inert atmosphere (Ar) to investigate the weight loss of both precursors, namely CNC and CNT, during pyrolysis. CNT-CNC-01 and CNT-CNC-02 represent the as-prepared CNT-CNC composites with weight ratio of 100:11.21 for CNT and CNC in Figure 2, which were used for calculating the composition of CNT and CNC as shown in Tables S1, S2, and S3 (Supplementary Materials). The CNC exhibited the main weight loss in the temperature range of $250-400{ }^{\circ} \mathrm{C}$, at which depolymerization of cellulose occurs along with dehydration [20]; thereafter, the weight loss slowly progressed (Figure 2). The results indicated that the weight loss of CNT began at approximately $800^{\circ} \mathrm{C}$ and exhibited an increased weight loss with increases in temperature. Based on the result, we selected two points of temperature for pyrolysis, namely $800{ }^{\circ} \mathrm{C}$ at which CNC involves a change in chemical composition while CNT is not significantly affected, and $1300{ }^{\circ} \mathrm{C}$ as a designated temperature at which both CNC and CNT undergo thermal decomposition.

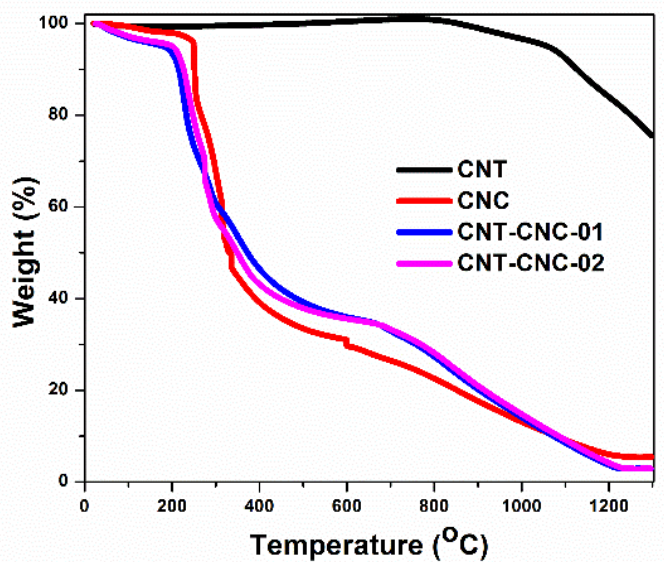

Figure 2. Thermogravimetric analysis data of carbon nanotube (CNT), crystalline nanocellulose (CNC), and CNT-CNC.

We evaluated the effect of temperature on the structural change in the precursors, as shown in Figure 3. In the case of CNT composite films, the XRD patterns were not significantly different (Figure 3a). When looking into the peak at $\sim 44^{\circ}$, it showed a very broad peak and a maximum peak intensity at $\sim 44^{\circ}$, which was related to the (101) plane of CNT. In addition, the peak at $\sim 25^{\circ}$ corresponding to the (002) plane was also detected. It was noted that, when CNT was heat-treated at $800{ }^{\circ} \mathrm{C}$, the peaks related to the CNT phase did not show significant changes. The comparison of XRD patterns of the CNC films indicated a broad peak at $\sim 15^{\circ}$, related to and (110) planes [21], while a difference in the peak at $2 \theta=22.2^{\circ}$ was assigned to the (200) plane. The CNC showed a broad peak at $2 \theta=22.2^{\circ}$ after heat treatment at $800{ }^{\circ} \mathrm{C}$, thereby indicating a very low crystallinity. Meanwhile, when comparing the $\mathrm{XRD}$ peak of $\mathrm{CNC}_{1300}$ at $\sim 22^{\circ}$ to that of $\mathrm{CNC}_{800}$, the $\mathrm{CNC}_{800}$ sample showed a very 
broad peak over the range of $\sim 10^{\circ}$ due to the very low crystallinity. On the other hand, the $\mathrm{CNC}_{1300}$ sample exhibited an abrupt small peak at $\sim 22^{\circ}$, which could be due to a partial graphitization in a small portion of CNC. This explanation is in good agreement with the Raman result, where the $\mathrm{I}_{\mathrm{G}} / \mathrm{I}_{\mathrm{D}}$ value of $\mathrm{CNC}_{1300}$ (1.36) was higher than that of $\mathrm{CNC}_{800}$ (0.99) (discussed later). This implied that crystallized cellulose, i.e., CNC, was carbonized at $800^{\circ} \mathrm{C}$ and tended to form graphitized carbon during carbonization at $1300{ }^{\circ} \mathrm{C}$. The partial graphitization that was achieved at the relatively low temperature of $1300^{\circ} \mathrm{C}$ was related to the highly crystalline structure of $\mathrm{CNC}$. For the CNT-CNC composite films, the XRD pattern of $\mathrm{CNT}-\mathrm{CNC}_{70}$ was similar to that of $\mathrm{CNC}_{70}$. It was noted that the peaks related to CNT, as shown in Figure 3a, were not detected in CNT-CNC composite films (Figure 3c), which could be due to the very small amount of CNT in CNC. After being heat-treated at $800{ }^{\circ} \mathrm{C}$ and $1300{ }^{\circ} \mathrm{C}$, the peaks related to $\mathrm{CNC}$ functional groups disappeared and a broad peak corresponding to carbonized carbon peaks was observed.
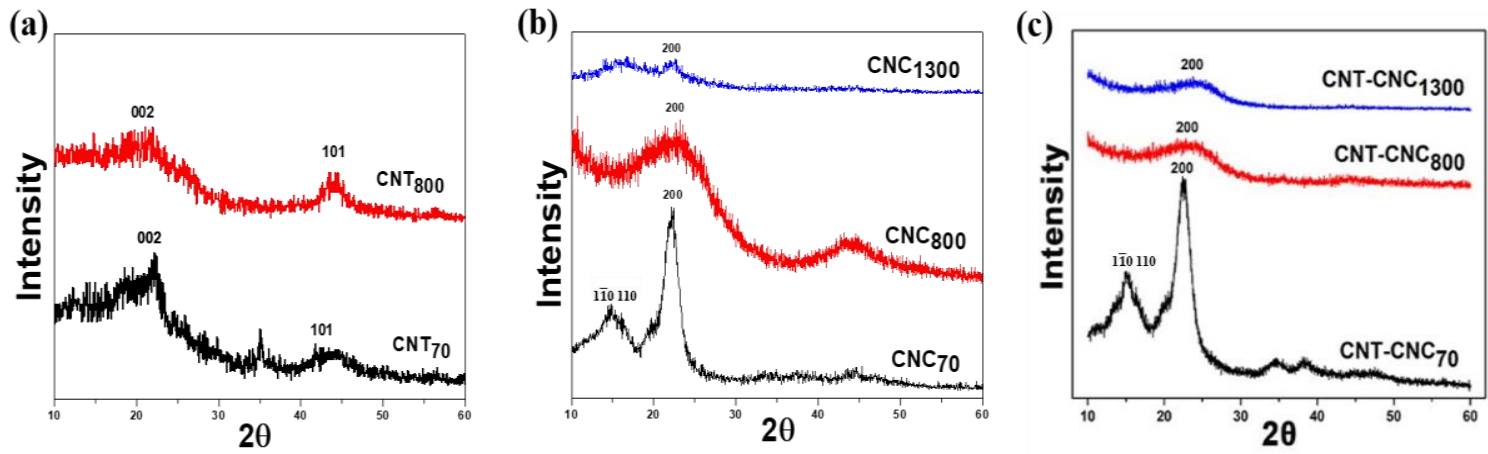

Figure 3. X-ray diffraction (XRD) pattern of (a) CNT at $70{ }^{\circ} \mathrm{C}$ and $800^{\circ} \mathrm{C},(\mathbf{b}) \mathrm{CNC}$ at $70{ }^{\circ} \mathrm{C}, 800{ }^{\circ} \mathrm{C}$, and $1300{ }^{\circ} \mathrm{C}$, and (c) CNT-CNCs at $70{ }^{\circ} \mathrm{C}, 800{ }^{\circ} \mathrm{C}$, and $1300{ }^{\circ} \mathrm{C}$.

Carbonization of CNC was also confirmed by the appearance of Raman bands that characterize $s p^{2}$ hybridized carbon, i.e., the G-band (approximately $1580 \mathrm{~cm}^{-1}$ ) and D-band (approximately $1350 \mathrm{~cm}^{-1}$ ) after pyrolysis (Figure $4 \mathrm{a}-\mathrm{c}$ ). The intensity ratio of G-band and D-band $\mathrm{CNT}, \mathrm{I}_{\mathrm{G}} / \mathrm{I}_{\mathrm{D}}$, was approximately 2.0 before hydrolysis and slightly decreased to 1.8 and to 1.0 with heat treatments at $800{ }^{\circ} \mathrm{C}$ and at $1300{ }^{\circ} \mathrm{C}$ (Figure $4 \mathrm{~d}$ ), respectively. The result implied a higher portion of defects generated via heat treatment (discussed later).

The results of the controlled experiments indicated that the composition ratio of CNT to CNC in CNT-CNC 800 and $\mathrm{CNT}_{-} \mathrm{CNC}_{1300}$ was 0.57:0.43 and 0.24:0.76, respectively (the weight loss of CNC and CNT based on the temperature is described in Tables S1-S3, Supplementary Materials). The resultant CNT-CNC films did not shrink in plane after the pyrolysis, and the thickness of the composite changed from $70 \mu \mathrm{m}\left(\mathrm{CNT}-\mathrm{CNC}_{70}\right)$ to $4 \mu \mathrm{m}\left(\mathrm{CNT}-\mathrm{CNC}_{800}\right)$ and $13 \mu \mathrm{m}\left(\mathrm{CNT}-\mathrm{CNC}_{1300}\right)$. It was noted that the $\mathrm{CNT}-\mathrm{CNC}_{1300}$ electrode was thicker than the $\mathrm{CNT}-\mathrm{CNC}_{800}$ electrode after pyrolysis, which could be due to the higher amount of composite solution applied. Practically, when a low amount of solution was used for the CNT- $\mathrm{CNC}_{1300}$ electrode, it was hard to develop good free-standing electrodes. The resultant films retained their flexibility (Figures S4-S5, Supplementary Materials). The result implied that the thermal decomposition did not significantly damage the inter-connected network of CNTs in plane, and that the volume change caused by CNC decomposition was offset by the compression along the thickness.

Pyrolysis changed the morphology of the composite films based on the temperature. A comparison

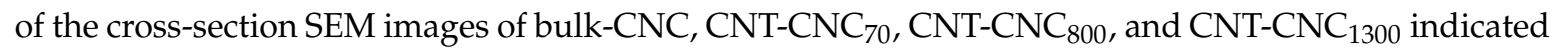
the clear difference in morphology (Figure 5). 
(a)
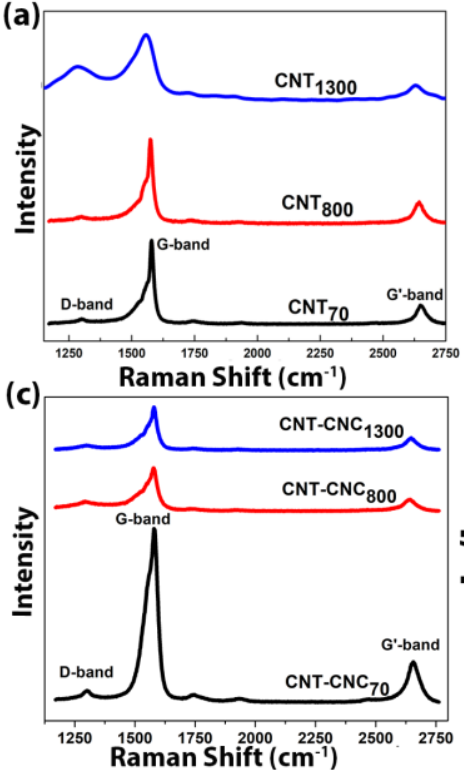
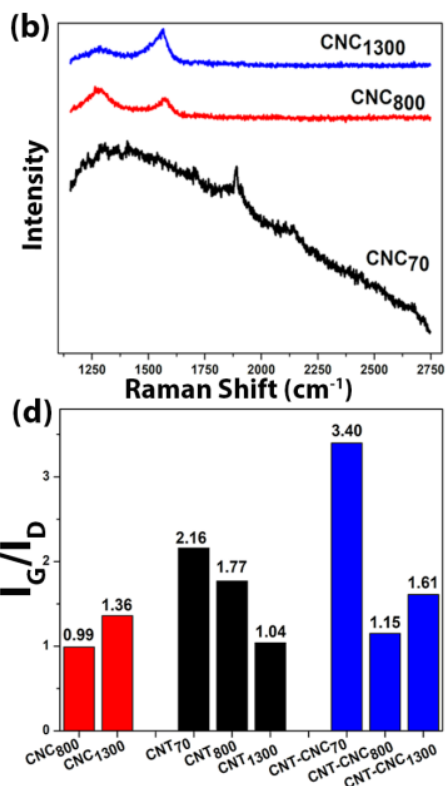

Figure 4. Raman spectra of (a) $\mathrm{CNT}$ at $70{ }^{\circ} \mathrm{C}, 800^{\circ} \mathrm{C}$, and $1300^{\circ} \mathrm{C},\left(\right.$ b) $\mathrm{CNC}$ at $70{ }^{\circ} \mathrm{C}, 800^{\circ} \mathrm{C}$, and $1300{ }^{\circ} \mathrm{C}$, and (c) CNT-CNCs at $70{ }^{\circ} \mathrm{C}, 800{ }^{\circ} \mathrm{C}$, and $1300{ }^{\circ} \mathrm{C}$. (d) Comparison of $\mathrm{I}_{\mathrm{G}} / \mathrm{I}_{\mathrm{D}}$ ratio with various samples.
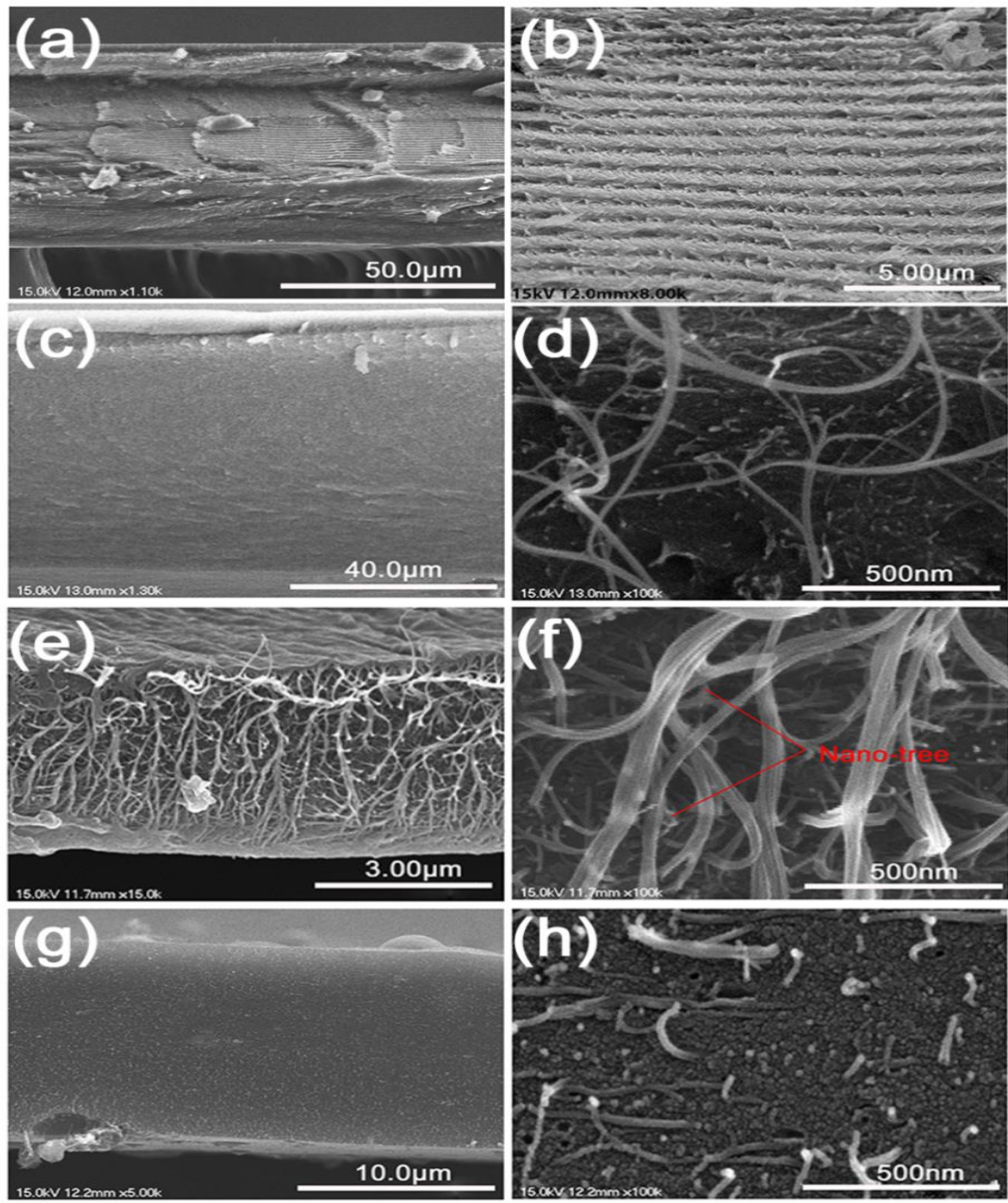

Figure 5. Cross-section morphologies of $(\mathbf{a}, \mathbf{b}) \mathrm{CNC}_{70},(\mathbf{c}, \mathbf{d}) \mathrm{CNT}-\mathrm{CNC}_{70},(\mathbf{e}, \mathbf{f}) \mathrm{CNT}-\mathrm{CNC}_{800}$, and $(\mathbf{g}, \mathbf{h}) \mathrm{CNT}-\mathrm{CNC}_{1300}$. 
The pure CNC film presented a chiral nematic nanostructure that was preserved from a mesophase of $\mathrm{CNC}$ suspension $[22,23]$ on slow evaporation (Figure $5 \mathrm{a}-\mathrm{b}$ ). However, with respect to $\mathrm{CNT}-\mathrm{CNC}_{70}$, CNCs did not exhibit chirality and, instead, formed a dense matrix embedding CNTs (Figure 5c-d). When looking into the Brunauer-Emmett-Teller (BET) results (Figure S8, Supplementary Materials), the $\mathrm{CNT}-\mathrm{CNC}_{800}$ sample demonstrated the highest $\mathrm{N}_{2}$-sorption isotherm with a high pore volume (Table S4, Supplementary Materials) and various pore diameters compared to other samples. It was noted that surface area of the $\mathrm{CNT}-\mathrm{CNC}_{1300}$ sample was much lower than that of the CNT-CNC 800 sample, where the calculated surface area corresponded to $1184.2 \mathrm{~m}^{2} \cdot \mathrm{g}^{-1}$ for $\mathrm{CNT}-\mathrm{CNC}_{800}$ and $278.2 \mathrm{~m}^{2} \cdot \mathrm{g}^{-1}$ for $\mathrm{CNT}-\mathrm{CNC}_{1300}$. The different form of the isotherms and the significant change of the surface area between $\mathrm{CNT}-\mathrm{CNC}_{800}$ and $\mathrm{CNT}-\mathrm{CNC}_{1300}$ samples could be due to the distinguishable morphologies. In the morphology of $\mathrm{CNT}-\mathrm{CNC}_{800}$, large empty spaces were formed between the inter-connected three-dimensional (3D) networks of intact CNTs (Figure 5e-f). Under the static in-plane dimension by the CNT network, the loss of CNC appeared to generate the spaces. However, the cross-section of $\mathrm{CNT}-\mathrm{CNC}_{1300}$ exhibited a different morphology, wherein short CNTs with a broken end were embedded in the coarse CNC matrix (Figure 5g-h) (see Figures S6 and S7, Supplementary Materials, for further morphology data). This explanation is in good agreement with the BET results showing a high surface area in the $\mathrm{CNT}-\mathrm{CNC}_{800}$ composite film.

Electrical conductivity was also significantly affected by the heat treatment. CNT-CNC 70 exhibited almost non-conductive behavior (electric conductivity of approximately $0 \mathrm{~S} \cdot \mathrm{cm}^{-1}$ ) (Figure 6), presumably because several insulating CNCs adhered to the surface of the CNTs and, thus, did not reach critical percolation. Conversely, as shown in the morphology of $\mathrm{CNT}-\mathrm{CNC}_{800}$, the restored long-range connectivity of CNTs recreated an electron-conducting pathway, thereby enhancing electrical conductivity (approximately $400 \mathrm{~S} \cdot \mathrm{cm}^{-1}$ ). The higher conductivity of CNT-CNC 1300 (approximately $500 \mathrm{~S} \cdot \mathrm{cm}^{-1}$ ) was attributed to the fact that the partially graphitized carbonaceous CNC (which is conducive and able to closely contact with CNTs due to their strong $\pi-\pi$ interactions [24]) was "welded" into the surface of CNTs, thereby significantly lowering the contact resistance despite the existence of broken CNTs.

(a)

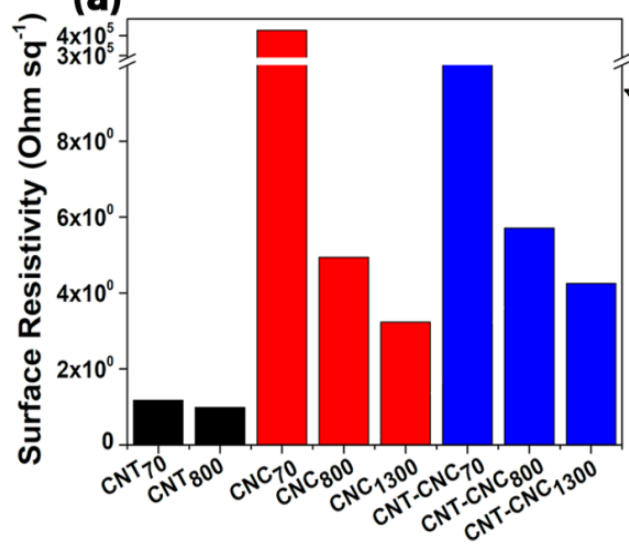

(b)

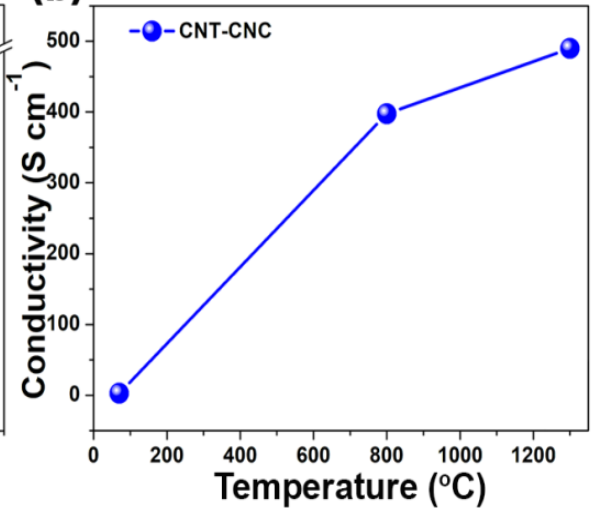

Figure 6. (a) Surface resistivity of various samples. (b) Conductivity of CNT-CNCs with different annealing temperatures.

The as-prepared materials were applied as anodes for lithium-ion batteries. The charge/discharge voltage profiles of as-prepared electrodes were analyzed. Firstly, we evaluated anodic activity using pure $\mathrm{CNC}$ and $\mathrm{CNT}$. It was noted that electrochemical reactions of the $\mathrm{CNC}_{70}$ electrode were absent, and this illustrated the absence of electrochemically active components. In the case of the $\mathrm{CNC}_{800}$ electrode, the first discharge and charge capacities were $168 \mathrm{mAh} \cdot \mathrm{g}^{-1}$ and $130 \mathrm{mAh} \cdot \mathrm{g}^{-1}$, respectively, corresponding to a Coulombic efficiency of $77 \%$, while the $\mathrm{CNC}_{1300}$ electrode exhibited a discharge/charge capacity of $236 \mathrm{mAh} \cdot \mathrm{g}^{-1} / 130 \mathrm{mAh} \cdot \mathrm{g}^{-1}$ with a Coulombic efficiency of $55 \%$ 
(Figures S9b-c, Supplementary Materials). Additionally, CNT electrodes exhibited a higher Coulombic efficiency of $91 \%$. However, low initial discharge and charge capacities of $250 \mathrm{mAh} \cdot \mathrm{g}^{-1}$ and $227 \mathrm{mAh} \cdot \mathrm{g}^{-1}$, respectively, were obtained (Figure S9a, Supplementary Materials).

Conversely, with respect to the CNT-CNC composite electrodes, Figure 7a shows the charge/discharge initial voltage profiles of CNT-CNC 800 at a current density of $232 \mathrm{~mA} \cdot \mathrm{g}^{-1}$ with a voltage range from 0.01 to $2.0 \mathrm{~V}$. The initial discharge and charge capacities were observed as 3280 and $478 \mathrm{mAh} \cdot \mathrm{g}^{-1}$, respectively, corresponding to a low initial Coulombic efficiency of $14.6 \%$. This irreversible capacity of the CNT-based electrodes could be limited by the control of the inserted lithium [25]. The discharge/charge capacities quickly decreased during the next few cycles and maintained a reversible capacity of $608 \mathrm{mAh} \cdot \mathrm{g}^{-1}$ to form the third cycle. The phenomenon was attributed to various reasons such as the formation of the solid electrolyte interphase (SEI) layer on the surface of the electrode [26-28], the oxygenated functional group on the surface electrode [28], and intercalation of $\mathrm{Li}$ into the inner core and side wall of CNT [29]. Based on the aforementioned voltage profile analysis, it mainly focused on the discussion of the composite electrode $\mathrm{CNT}-\mathrm{CNC}_{800}$ with respect to the electrochemical performance. Figure $7 \mathrm{~b}$ shows the initial cyclic voltammograms of the CNT-CNC 800 electrode. The capacity-voltage (CV) curves of the CNT-CNC electrode indicated that lithium ions reversibly (de)intercalated into CNTs [29-31]. The CNT-CNC 800 electrode exhibited a broad peak at approximately $0.1 \mathrm{~V}$ and $0.4 \mathrm{~V}$ in the initial cycle, and this can be related to the lithium deintercalated from the CNTs. Specifically, at the potential of $0.16 \mathrm{~V}$, the current reached the highest point, thereby indicating the deintercalation of lithium ions from the carbon nanotube. Additionally, the peaks at $0.8 \mathrm{~V}$ and $1.25 \mathrm{~V}$ appeared in the first cycle and disappeared in the second cycle, thereby indicating the formation of the SEI layer. During the negative scan, the potential of lithium intercalated to CNTs approximately corresponded to $0.05 \mathrm{~V}$, and this was extremely close to $0 \mathrm{~V}$ versus the $\mathrm{Li}^{+} / \mathrm{Li}$ reference. From the second cycle, the intensity of redox peaks was maintained, thereby illustrating stable and reversible electrochemical reactions.
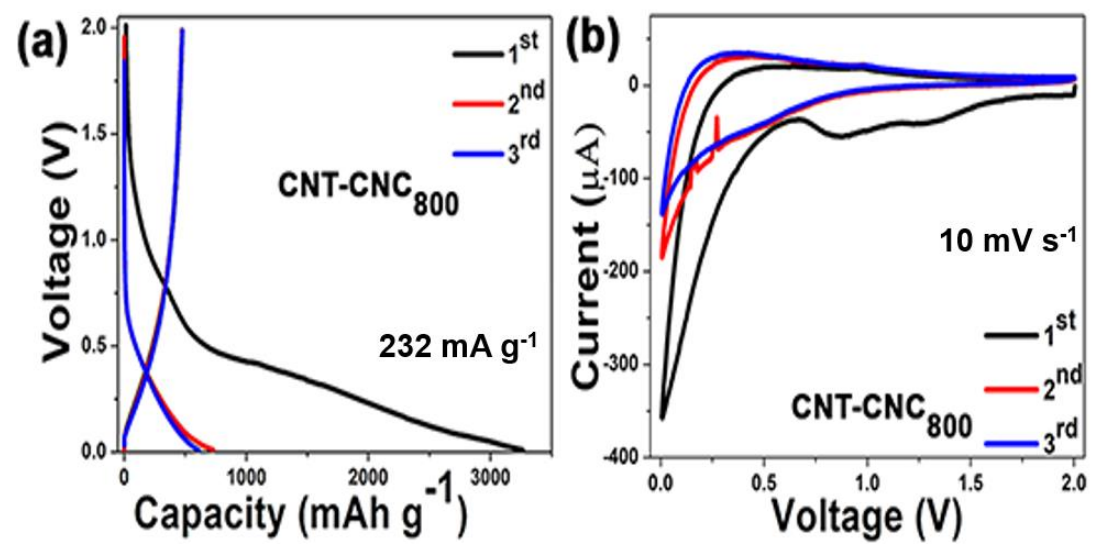

Figure 7. Electrochemical performance data of the composite electrodes. (a) Initial voltage profiles of the $\mathrm{CNT}-\mathrm{CNC}_{800}$ electrode. (b) Cyclic voltammograms of the $\mathrm{CNT}-\mathrm{CNC}_{800}$ electrode.

Figure 8a shows the discharge capacities of various samples that were developed at different annealing temperatures including $70{ }^{\circ} \mathrm{C}, 800{ }^{\circ} \mathrm{C}$, and $1300^{\circ} \mathrm{C}$. A free-standing bare $\mathrm{CNT}$ electrode developed with PVDF binder $\left(\mathrm{CNT}_{800}\right)$ was also tested to compare the effectiveness of CNCs on the electrochemical performance. With respect to bare $\mathrm{CNT}$, the capacity values were approximately $200 \mathrm{mAh} \cdot \mathrm{g}^{-1}$. However, the capacity was low when compared to that of CNT-CNC 800 (discussed below) due to the introduction of PVDF, which can act as an insulator although it can generate flexibility in the CNT film [32-36]. In the case of the sample with the annealing condition at $70{ }^{\circ} \mathrm{C}$, it did not demonstrate any electrochemical reactions of the CNT-CNC electrode, and this resulted in a capacity corresponding to zero value. As shown in Figure 6, the result of conductivity confirmed that CNC at the annealing temperature of $70{ }^{\circ} \mathrm{C}$ exhibited extremely high resistance, and this was inappropriate 
for use as an electrode. It was noted that the electrochemical performance significantly improved with increases in the annealing temperature. For example, the $\mathrm{CNC}_{800}$ electrode exhibited an initial discharge capacity of $586 \mathrm{mAh} \cdot \mathrm{g}^{-1}$. However, it exhibited a gradual decrease in capacity after a few cycles and decreased to zero at the 120th cycle. While conducting heat treatment at $1300{ }^{\circ} \mathrm{C}$, there was also no significant improvement in capacities. Comparatively, in the case of CNT-CNC electrodes, the electrochemical performance was significantly different based on the applied annealing temperature. With respect to the $\mathrm{CNT}-\mathrm{CNC}_{1300}$ electrode, the capacity was significantly lower than that of the $\mathrm{CNT}-\mathrm{CNC}_{800}$ electrode, and this delivered a discharge capacity of $140 \mathrm{mAh} \cdot \mathrm{g}^{-1}$ after 120 cycles. The capacity values of $\mathrm{CNT}-\mathrm{CNC}_{1300}$ were similar to those of the bare $\mathrm{CNT}$ electrode. Given the application of extremely high temperature (i.e., $1300^{\circ} \mathrm{C}$ ), the $\mathrm{CNC}$ decomposed. In actuality, nearly $98 \%$ of CNC was degraded, as shown in Table S3 (Supplementary Materials). Furthermore, with respect to the SEM images in Figures S6h and S7h (Supplementary Materials) for the CNT-CNC 1300 electrode, the CNT-CNT network was clearly reduced and broken. Furthermore, the electrode was extremely brittle and weakened. Meanwhile, with respect to the $\mathrm{CNT}-\mathrm{CNC}_{800}$ electrode, it exhibited the highest capacity with significant stability, as shown in Figure 8a,d. Its discharge capacity was approximately $495 \mathrm{mAh} \cdot \mathrm{g}^{-1}$, and it maintained a capacity of $443 \mathrm{mAh} \cdot \mathrm{g}^{-1}$ after $120 \mathrm{cycles}$, thereby illustrating a good capacity retention of $89 \%$. The SEM images of the CNT-CNC 800 sample (Figure 5e,f) exhibited an interesting network morphology between CNC and CNT. The cross-section images proved that CNT formed a good network with the product of CNC decomposition during heat treatment. Additionally, it should be noted that CNTs exhibited a "nano-tree-like" shape with a good inter-connection and suitable distances between the trees (Figure 5f) [37]. Its morphology generated an increase in the surface area of the electrode, and this was approximately $1180 \mathrm{~m}^{2} \cdot \mathrm{g}^{-1}$. Furthermore, $43 \%$ of the CNC was decomposed and disappeared based on the TGA results (Figure 2); thus, there were free spaces in the network. Therefore, the developed film was more anodic-capable, albeit still flexible. Furthermore, in the case of $\mathrm{CNT}-\mathrm{CNC}_{800}, \mathrm{CNT}$ maintained its original structure well, which could have the ability to absorb two lithium layers per one carbon layer to form $\mathrm{Li}_{2} \mathrm{C}_{6}$ [38]. This phenomenon was comprehensively proven in a previous study. Numerous CNT edges absorb Li atoms; as a result, the theoretical capacity of the CNT-CNC electrode could exceed the theoretical capacity $\left(372 \mathrm{mAh} \cdot \mathrm{g}^{-1}\right)$ and reach high capacity values $\left(\sim 744 \mathrm{mAh} \cdot \mathrm{g}^{-1}\right)$ [39-41]. Based on the information, it is proposed that the CNT-CNC electrode that is appropriately heat-treated exhibits high potential for the application of flexible LIBs.

Figure $8 \mathrm{~b}$ shows the electrochemical impedance spectroscopic (EIS) images for the as-prepared electrode. The EIS analysis followed the modeling of $\mathrm{R}_{\mathrm{s}}-\left(\mathrm{R}_{\mathrm{ct}} \mid \mathrm{W}-\mathrm{Q}_{\mathrm{dl}}\right)$ and Nyquist plot for $\mathrm{CNT}-\mathrm{CNC} \mathrm{C}_{800}$ electrode after the third, 10th, 50th, and 100th cycles. The first semicircle at high frequency corresponded to the migration of Li ions via the passivation film (such as the SEI), and the second semicircle at the intermediate frequency corresponded to the charge transfer reaction $[42,43]$. The linear portion was attributed to semi-infinite diffusion conditions for the diffusion of lithium ions in carbon nanotubes [44] because the diffusion of lithium ions in the carbon nanotubes was considerably slower than that in an electrolyte solution [43]. It is noted that heat treatment significantly affected the resistance of the electrode for the CNT-CNC composite. For example, the $\mathrm{R}_{\mathrm{ct}}$ value of $\mathrm{CNT}-\mathrm{CNC}_{70}$ was extremely high $(4710 \Omega)$, and this was related to the absence of electrochemical reactions as discussed earlier. Additionally, the $\mathrm{CNT}-\mathrm{CNC}_{1300}$ electrode indicated a mild increase in $\mathrm{R}_{\mathrm{ct}}$ value corresponding to $241 \Omega$ due to the effects of the CNT decomposition, while $C N T-C C_{800}$ exhibited an $R_{c t}$ value of $134 \Omega$. The resistance values of $\mathrm{CNT}-\mathrm{CNC}_{800}$ and $\mathrm{CNT}-\mathrm{CNC}_{1300}$ were comparable to that of the CNT electrode $(105 \Omega)$, thereby illustrating the positive impact of heat treatment on decreasing the resistivity of the composite electrodes.

Furthermore, CNT-CNC electrodes exhibited excellent rate performances at different current densities ranging from 100 to $5000 \mathrm{~mA} \cdot \mathrm{g}^{-1}$, as shown in Figure $8 \mathrm{c}$. The CNT-CNC 1300 electrode showed an average capacity of $250 \mathrm{mAh} \cdot \mathrm{g}^{-1}$ at a current density of $100 \mathrm{~mA} \cdot \mathrm{g}^{-1}$. When current density increased to $5000 \mathrm{~mA} \cdot \mathrm{g}^{-1}$, it maintained an average capacity of $150 \mathrm{mAh} \cdot \mathrm{g}^{-1}$ corresponding 
to a capacity retention of $\sim 60 \%$. Meanwhile, in the case of the CNT-CNC 800 electrode, the capacity at $100 \mathrm{~mA} \cdot \mathrm{g}^{-1}$ was approximately $500 \mathrm{mAh} \cdot \mathrm{g}^{-1}$ with good stability. When the current density increased to $5000 \mathrm{~mA} \cdot \mathrm{g}^{-1}$, a reversible capacity of $182 \mathrm{mAh} \cdot \mathrm{g}^{-1}$ was obtained by demonstrating a capacity retention of approximately $\sim 40 \%$. When the current density recovered to $100 \mathrm{~mA} \cdot \mathrm{g}^{-1}$, the CNT-CNC $\mathrm{CN0}_{80}$ electrode still exhibited a good reversible capacity of $450 \mathrm{mAh} \cdot \mathrm{g}^{-1}$ by demonstrating a capacity restoration of $90 \%$. However, it was noted that, even though the capacity values of the $\mathrm{CNT}-\mathrm{CNC}_{800}$ electrode at different current densities were higher than those of the $\mathrm{CNT}-\mathrm{CNC}_{1300}$ electrode, the capacity retentions of the $\mathrm{CNT}-\mathrm{CNC}_{1300}$ electrode based on the capacity values at $100 \mathrm{~mA} \cdot \mathrm{g}^{-1}$ were higher than those of $\mathrm{CNT}-\mathrm{CNC}_{800}$. Therefore, even though both $\mathrm{CNT}-\mathrm{CNC}_{800}$ and $\mathrm{CNT}-\mathrm{CNC}_{1300}$ electrodes demonstrated good rate performance, we can draw a conclusion that the $\mathrm{CNT}-\mathrm{CNC}_{1300}$ electrode showed better rate performance compared to the $\mathrm{CNT}-\mathrm{CNC}_{800}$ electrode in terms of capacity retention, which could be due to the higher electrical conductivity of $\mathrm{CNT}-\mathrm{CNC}_{1300}$ (Figure 6). Finally, we compared the performance of the $\mathrm{CNT}-\mathrm{CNC}_{800}$ electrode with various flexible electrodes with CNTs, as shown in Table S5 (Supplementary Materials), and they exhibited simple preparation and superior electrochemical performance.

(a)

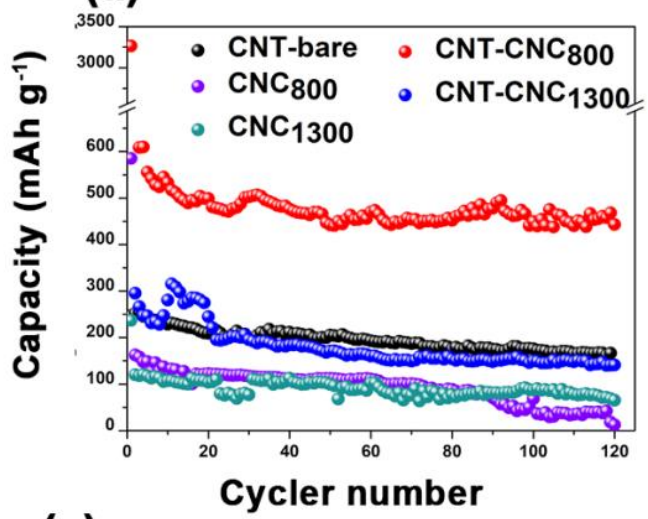

(c)

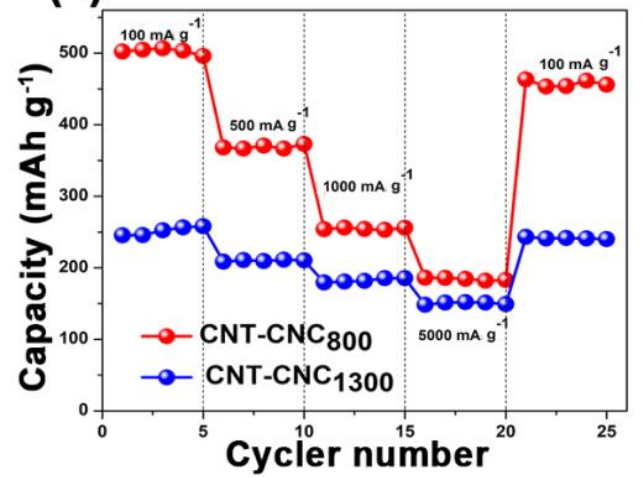

(b)

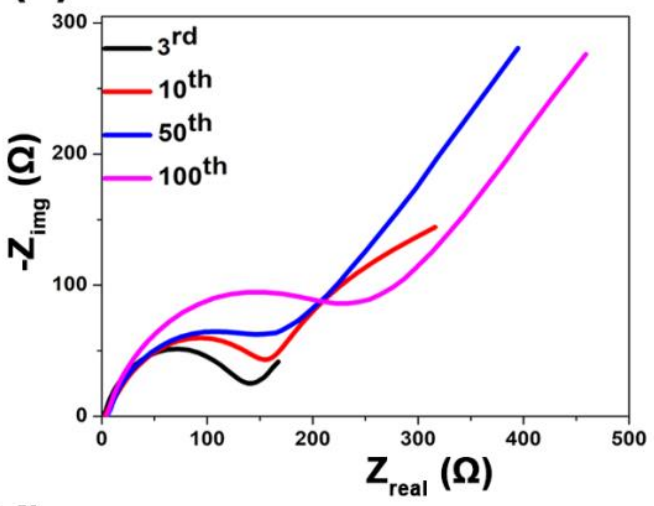

(d)

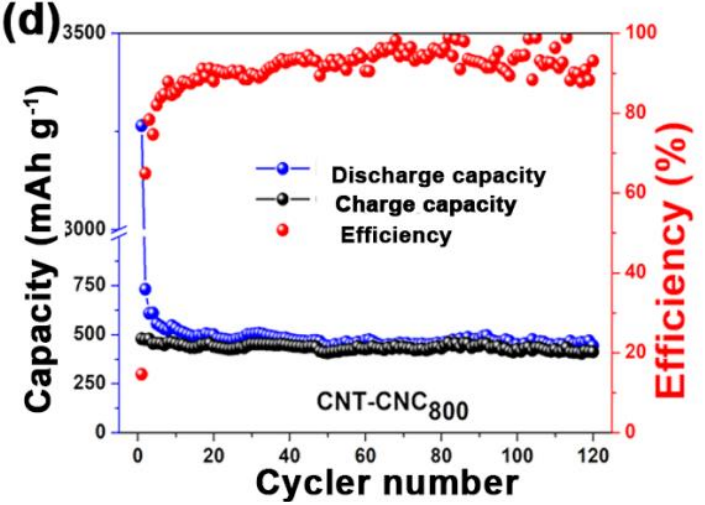

Figure 8. (a) Cyclic performance of bare $\mathrm{CNT}$ bare, $\mathrm{CNC}_{800}, \mathrm{CNC}_{1300}, \mathrm{CNT}-\mathrm{CNC}_{800}$, and $\mathrm{CNT}-\mathrm{CNC}_{1300}$. (b) Electrochemical impedance spectroscopic measurement for $\mathrm{CNT}-\mathrm{CNC}_{800}$ after the third, 10th, 50th, and 100th cycles. (c) Rate performance of $\mathrm{CNT}-\mathrm{CNC}_{800}$ and $\mathrm{CNT}-\mathrm{CNC}_{1300}$. (d) Cyclic performance with respect to the Coulombic efficiency of $\mathrm{CNT}-\mathrm{CNC}_{800}$ for 120 cycles.

\section{Conclusions}

In the study, pliable self-standing CNT-CNC electrodes with significant electrochemical performance were achieved via a simple aqueous-based preparation method. Specifically, CNC was applied to act as the binding constitute to generate a self-standing CNT electrode, leading to stable dispersity of $\mathrm{CNT}$ in the $\mathrm{CNC}$ solution, and the heat treatment process introduced new characteristics, including conductive CNC and free spaces in the CNT-CNC structure. The sizes and structures of the pores and the porosity critically affected their battery performance. With respect to 
the electrodes, hierarchical microporous-mesoporous structures were desirable in terms of improving the contact area of the electrode-electrolyte, decreasing the diffusion resistance of electrolyte ions, and shortening the diffusion length of the electrolyte ions. Given this viewpoint, the porous structure of $\mathrm{CNT}_{-} \mathrm{CNC}_{800}$ exhibited outstanding electrochemical performance. However, it was recognized that carbonization and/or graphitization of CNT-CNC composite films at various annealing temperature are also important to achieve more optimized electrochemical performance, which could be the basis of future work. In summary, the $\mathrm{CNT}-\mathrm{CNC}_{800}$ electrode developed in this study is a promising candidate for effective lithium-ion storage.

Supplementary Materials: The following are available online at http://www.mdpi.com/2079-4991/9/4/655/s1: Figure S1: The dependence of surface charge on the $\mathrm{pH}$; Figure S2: Illustration of (a) solution CNCs, (b) solution CNT-CNC, and (c) aqueous CNT; Figure S3: Ultraviolet (UV)-visible absorption spectra; Table S1: The initial composition of the electrode; Table S2: The composition of the electrode at $800^{\circ} \mathrm{C}$; Table S3: The composition of the electrode at $1300^{\circ} \mathrm{C}$; Figure S4: Images of free-standing electrodes with different annealing temperatures; Figure S5: Images of pliable electrodes; Figure S6: SEM images (surface section); Figure S7: SEM images (cross-section); Figure S8: Brunauer-Emmett-Teller (BET); Figure S9: Initial voltage profiles; Figure S10: Cyclic voltammograms; Figure S11: TEM images of CNTs; Table S4: Specific surface area of the as-prepared electrode films; Table S5: Comparison of the performance for various flexible electrodes with CNTs.

Author Contributions: Writing—original draft preparation, H.K.N. and J.B.; writing—review and editing, J.H. and M.S.P.; conceptualization, S.J.P.; supervision, I.T.K.

Funding: This work was supported by a National Research Foundation of Korea (NRF) grant funded by the Korean government (MSIT) (NRF-2018R1A1A1A05018332). This work was supported by the Korea Institute of Energy Technology Evaluation and Planning (KETEP) and the Ministry of Trade, Industry, and Energy (MOTIE) of the Republic of Korea (No. 20194030202290).

Conflicts of Interest: The authors declare no conflicts of interest.

\section{References}

1. Liu, X.-M.; Huang, Z.D.; Oh, S.W.; Zhang, B.; Ma, P.-C.; Yuen, M.M.F.; Kim, J.-K. Carbon nanotube (cnt)-based composites as electrode material for rechargeable li-ion batteries: A review. Compos. Sci. Technol. 2012, 72, 121-144. [CrossRef]

2. Rolison, D.R.; Long, J.W.; Lytle, J.C.; Fischer, A.E.; Rhodes, C.P.; McEvoy, T.M.; Bourg, M.E.; Lubers, A.M. Multifunctional 3d nanoarchitectures for energy storage and conversion. Chem. Soc. Rev. 2009, 38, $226-252$. [CrossRef]

3. Long, J.W.; Dunn, B.; Rolison, D.R.; White, H.S. Three-dimensional battery architectures. Chem. Rev. 2004, 104, 4463-4492. [CrossRef] [PubMed]

4. Landi, B.J.; Ganter, M.J.; Cress, C.D.; DiLeo, R.A.; Raffaelle, R.P. Carbon nanotubes for lithium ion batteries. Energy Environ. Sci. 2009, 2, 638-654. [CrossRef]

5. Marks, T.; Trussler, S.; Smith, A.J.; Xiong, D.; Dahn, J.R. A guide to li-ion coin-cell electrode making for academic researchers. J. Electrochem. Soc. 2011, 158, A51-A57. [CrossRef]

6. Dai, H. Carbon nanotubes: Opportunities and challenges. Surf. Sci. 2002, 500, 218-241. [CrossRef]

7. Wood, D.L.; Li, J.; Daniel, C. Prospects for reducing the processing cost of lithium ion batteries. J. Power Sources 2015, 275, 234-242. [CrossRef]

8. Hirsch, A. Functionalization of single-walled carbon nanotubes. Angew. Chem. Int. Ed. 2002, 41, $1853-1859$. [CrossRef]

9. Hamedi, M.M.; Hajian, A.; Fall, A.B.; Hakansson, K.; Salajkova, M.; Lundell, F.; Wagberg, L.; Berglund, L.A. Highly conducting, strong nanocomposites based on nanocellulose-assisted aqueous dispersions of single-wall carbon nanotubes. ACS Nano 2014, 8, 2467-2476. [CrossRef]

10. Du, X.; Zhang, Z.; Liu, W.; Deng, Y. Nanocellulose-based conductive materials and their emerging applications in energy devices-A review. Nano Energy 2017, 35, 299-320. [CrossRef]

11. Chen, W.; Yu, H.; Lee, S.-Y.; Wei, T.; Li, J.; Fan, Z. Nanocellulose: A promising nanomaterial for advanced electrochemical energy storage. Chem. Soc. Rev. 2018, 47, 2837-2872. [CrossRef]

12. Fall, A.B.; Lindström, S.B.; Sundman, O.; Ödberg, L.; Wågberg, L. Colloidal stability of aqueous nanofibrillated cellulose dispersions. Langmuir 2011, 27, 11332-11338. [CrossRef] 
13. Hajian, A.; Lindström, S.B.; Pettersson, T.; Hamedi, M.M.; Wågberg, L. Understanding the dispersive action of nanocellulose for carbon nanomaterials. Nano Lett. 2017, 17, 1439-1447. [CrossRef]

14. Niu, Q.; Gao, K.; Shao, Z. Cellulose nanofiber/single-walled carbon nanotube hybrid non-woven macrofiber mats as novel wearable supercapacitors with excellent stability, tailorability and reliability. Nanoscale 2014, 6, 4083-4088. [CrossRef]

15. Kang, Y.J.; Chun, S.J.; Lee, S.S.; Kim, B.Y.; Kim, J.H.; Chung, H.; Lee, S.Y.; Kim, W. All-solid-state flexible supercapacitors fabricated with bacterial nanocellulose papers, carbon nanotubes, and triblock-copolymer ion gels. ACS Nano 2012, 6, 6400-6406. [CrossRef]

16. Gao, K.; Shao, Z.; Wang, X.; Zhang, Y.; Wang, W.; Wang, F. Cellulose nanofibers/multi-walled carbon nanotube nanohybrid aerogel for all-solid-state flexible supercapacitors. RSC Adv. 2013, 3, 15058-15064. [CrossRef]

17. Zhu, H.; Shen, F.; Luo, W.; Zhu, S.; Zhao, M.; Natarajan, B.; Dai, J.; Zhou, L.; Ji, X.; Yassar, R.S.; et al. Low temperature carbonization of cellulose nanocrystals for high performance carbon anode of sodium-ion batteries. Nano Energy 2017, 33, 37-44. [CrossRef]

18. Mishra, S.; Kumaran, K.T.; Sivakumaran, R.; Pandian, S.P.; Kundu, S. Synthesis of pvdf/cnt and their functionalized composites for studying their electrical properties to analyze their applicability in actuation \& sensing. Colloids Surf. A Physicochem. Eng. Asp. 2016, 509, 684-696.

19. Bahr, J.L.; Mickelson, E.T.; Bronikowski, M.J.; Smalley, R.E.; Tour, J.M. Dissolution of small diameter single-wall carbon nanotubes in organic solvents? Chem. Commun. 2001, 193-194. [CrossRef]

20. Dumanl1, A.G.; Windle, A.H. Carbon fibres from cellulosic precursors: A review. J. Mater. Sci. 2012, 47, 4236-4250. [CrossRef]

21. Chen, W.; Yu, H.; Liu, Y.; Chen, P.; Zhang, M.; Hai, Y.J. Individualization of cellulose nanofibers from wood using high-intensity ultrasonication combined with chemical pretreatments. Carbohydr. Polym. 2011, 83, 1804-1811. [CrossRef]

22. Parker, R.M.; Frka-Petesic, B.; Guidetti, G.; Kamita, G.; Consani, G.; Abell, C.; Vignolini, S. Hierarchical self-assembly of cellulose nanocrystals in a confined geometry. ACS Nano 2016, 10, 8443-8449. [CrossRef]

23. Barbash, V.A.; Yaschenko, O.V.; Alushkin, S.V.; Kondratyuk, A.S.; Posudievsky, O.Y.; Koshechko, V.G. The effect of mechanochemical treatment of the cellulose on characteristics of nanocellulose films. Nanoscale Res. Lett. 2016, 11, 410. [CrossRef]

24. Li, Z.; Liu, J.; Thundat, T.G. Carbonized nanocellulose sustainably boosts the performance of activated carbon in ionic liquid supercapacitors. Meet. Abstr. 2016, MA2016-02, 1037. [CrossRef]

25. Arrebola, J.; Caballero, A.; Hernán, L.; Morales, J.; Olivares-Marín, M.; Gómez-Serrano, V.J. Improving the performance of biomass-derived carbons in li-ion batteries by controlling the lithium insertion process. J. Electrochem. Soc. 2010, 157, A791-A797. [CrossRef]

26. Eom, J.; Kwon, H. Improved lithium insertion/extraction properties of single-walled carbon nanotubes by high-energy ball milling. J. Mater. Res. 2008, 23, 2458-2466. [CrossRef]

27. Chen, J.; Liu, Y.; Minett, A.I.; Lynam, C.; Wang, J.; Wallace, G.G. Flexible, aligned carbon nanotube/conducting polymer electrodes for a lithium-ion battery. Chem. Mater. 2007, 19, 3595-3597. [CrossRef]

28. Frackowiak, E.; Gautier, S.; Gaucher, H.; Bonnamy, S.; Beguin, F. Electrochemical storage of lithium in multiwalled carbon nanotubes. Carbon 1999, 37, 61-69. [CrossRef]

29. Yang, Z.-H.; Wu, H.-Q. Electrochemical intercalation of lithium into carbon nanotubes. Solid State Ion. 2001, 143, 173-180. [CrossRef]

30. Shimoda, H.; Gao, B.; Tang, X.P.; Kleinhammes, A.; Fleming, L.; Wu, Y.; Zhou, O. Lithium intercalation into opened single-wall carbon nanotubes: Storage capacity and electronic properties. Phys. Rev. Lett. 2002, 88, 015502. [CrossRef]

31. Zhao, J.; Buldum, A.; Han, J.; Ping Lu, J. First-principles study of li-intercalated carbon nanotube ropes. Phys. Rev. Lett. 2000, 85, 1706-1709. [CrossRef]

32. Yoon, S.; Lee, S.; Kim, S.; Park, K.-W.; Cho, D.; Jeong, Y. Carbon nanotube film anodes for flexible lithium ion batteries. J. Power Sources 2015, 279, 495-501. [CrossRef]

33. Kang, C.; Patel, M.; Rangasamy, B.; Jung, K.-N.; Xia, C.; Shi, S.; Choi, W. Three-dimensional carbon nanotubes for high capacity lithium-ion batteries. J. Power Sources 2015, 299, 465-471. [CrossRef]

34. Ng, S.H.; Wang, J.; Guo, Z.P.; Chen, J.; Wang, G.X.; Liu, H.K. Single wall carbon nanotube paper as anode for lithium-ion battery. Electrochim. Acta 2005, 51, 23-28. [CrossRef] 
35. Xiong, Z.; Yun, Y.S.; Jin, H.-J. Applications of carbon nanotubes for lithium ion battery anodes. Materials 2013, 6, 1138-1158. [CrossRef] [PubMed]

36. Chew, S.Y.; Ng, S.H.; Wang, J.; Novák, P.; Krumeich, F.; Chou, S.L.; Chen, J.; Liu, H.K. Flexible free-standing carbon nanotube films for model lithium-ion batteries. Carbon 2009, 47, 2976-2983. [CrossRef]

37. Ouldhamadouche, N.; Achour, A.; Lucio-Porto, R.; Islam, M.; Solaymani, S.; Arman, A.; Ahmadpourian, A.; Achour, H.; Le Brizoual, L.; Djouadi, M.A.; et al. Electrodes based on nano-tree-like vanadium nitride and carbon nanotubes for micro-supercapacitors. J. Mater. Sci. Technol. 2018, 34, 976-982.

38. Liu, Y.; Xue, J.S.; Zheng, T.; Dahn, J.R. Mechanism of lithium insertion in hard carbons prepared by pyrolysis of epoxy resins. Carbon 1996, 34, 193-200. [CrossRef]

39. Mukherjee, R.; Thomas, A.V.; Datta, D.; Singh, E.; Li, J.; Eksik, O.; Shenoy, V.B.; Koratkar, N. Defect-induced plating of lithium metal within porous graphene networks. Nat. Commun. 2014, 5, 3710. [CrossRef]

40. Sonia, F.J.; Jangid, M.K.; Ananthoju, B.; Aslam, M.; Johari, P.; Mukhopadhyay, A. Understanding the li-storage in few layers graphene with respect to bulk graphite: Experimental, analytical and computational study. J. Mater. Chem. A 2017, 5, 8662-8679. [CrossRef]

41. Cheng, Q.; Okamoto, Y.; Tamura, N.; Tsuji, M.; Maruyama, S.; Matsuo, Y. Graphene-like-graphite as fast-chargeable and high-capacity anode materials for lithium ion batteries. Sci. Rep. 2017, 7, 14782. [CrossRef]

42. Yang, Z.-H.; Wu, H.-Q. The electrochemical impedance measurements of carbon nanotubes. Chem. Phys. Lett. 2001, 343, 235-240. [CrossRef]

43. Yang, Z.; Feng, Y.; Li, Z.; Sang, S.; Zhou, Y.; Zeng, L. An investigation of lithium intercalation into the carbon nanotubes by a.C. Impedance. J. Electroanal. Chem. 2005, 580, 340-347. [CrossRef]

44. Wang, G.X.; Ahn, J.-H.; Yao, J.; Lindsay, M.; Liu, H.K.; Dou, S.X. Preparation and characterization of carbon nanotubes for energy storage. J. Power Sources 2003, 119-121, 16-23. [CrossRef]

(C) 2019 by the authors. Licensee MDPI, Basel, Switzerland. This article is an open access article distributed under the terms and conditions of the Creative Commons Attribution (CC BY) license (http://creativecommons.org/licenses/by/4.0/). 